\title{
Nectin and Nectin-Like Molecules: Biology and Pathology
}

\author{
Jun Miyoshia ${ }^{a}$ Yoshimi Takai $^{b}$ \\ a Department of Molecular Biology, Osaka Medical Center for Cancer and Cardiovascular Diseases, Osaka, and \\ ${ }^{b}$ Osaka University Graduate School of Medicine, Faculty of Medicine, Suita, Japan
}

Key Words

Adherens Junction $\cdot \mathrm{Nectin} \cdot \mathrm{Necl} \cdot \mathrm{Rho} \cdot \mathrm{Rac} \cdot \mathrm{Cdc} 42 \cdot \mathrm{Rap}$

\begin{abstract}
Nectins and nectin-like molecules (Necls) are structurally related transmembrane proteins primarily involved in cell adhesion. Nectins and afadin, the adaptor or anchoring protein, stabilize the epithelium and endothelium and establish apical-basal polarity of epithelial cells, independently or in cooperation with other cell adhesion molecules. Necls facilitate cell-cell communication implicated in cell movement and proliferation, immune responses, and cancer cell phenotypes. Necls interact with nectins and specific ligands at cell-cell contacts, whereas Necls associate with integrin $\alpha v \beta 3$ and growth factor receptors on the same cell surface. Besides their roles in cell adhesion, nectins regulate the activities of Rho family small G proteins which play critical roles in maintaining the apical junctions of epithelial cells through reorganization of the actin cytoskeleton. Since mice lacking the Rho GDP-dissociation inhibitor (GDI) $\alpha$ show massive proteinuria and degeneration of renal epithelial cells, nectins and other cell adhesion molecules may play roles in the structural and functional aspects of renal diseases. Here we summarize our knowledge of nectins and Necls and discuss cell adhesion biology in the kidney.
\end{abstract}

Copyright $\odot 2007$ S. Karger AG, Basel

\section{Introduction}

In multicellular organisms, cell adhesion plays important roles in various cellular processes including morphogenesis, differentiation, proliferation, and migration $[1,2]$. The nectin and nectin-like molecule (Necl) superfamily has recently emerged as an immunoglobulin (Ig)like family that participates in calcium-independent cell adhesion [3]. They function as components of the epithelial junctional complexes, receptors for virion entry, tumor suppressors, and molecules involved in immune reactions. Based on their biochemical similarities, we have proposed the nectin and $\mathrm{Necl}$ families, with four and five members, respectively, in order to promote comprehensive understandings of these molecules and provide insights into their biology and pathology [3].

The apical junctions, namely tight junctions and adherens junctions, are sites of mechanical cell attachment regulated by dynamic changes in the actin cytoskeleton. Particularly, adherens junctions have prototypic roles for stabilizing the epithelium and establishing apical-basal polarity of epithelial cells. These functions have been elucidated by studies on nectins and cadherins that are two major cell adhesion molecules at adherens junctions. Nectin-based cell adhesion and cadherin-based cell adhesion function both individually and in combination to establish and maintain the mature apical junctions. Com-

\section{KARGER \\ Fax +41613061234 \\ E-Mail karger@karger.ch}

www.karger.com
(C) 2007 S. Karger AG, Basel

0250-8095/07/0276-0590\$23.50/0

Accessible online at:

www.karger.com/ajn
Prof. Yoshimi Takai

Department of Molecular Biology and Biochemistry

Osaka University Graduate School of Medicine, Faculty of Medicine

2-2 Yamada-oka, Suita 565-0871 (Japan)

Tel. +81 66879 3410, Fax +81 66879 3419, E-Mail ytakai@molbio.med.osaka-u.ac.jp 
ponents clustered at the junctional apparatus possess signaling capabilities that provide the means to integrate changes in morphology and gene expression during tissue and organ development [4]. Rho family small G proteins are important signal transducers downstream of nectins and cadherins, and regulate epithelial and endothelial barrier functions through regulation of both the actin cytoskeletal organization and the integrity of intercellular junctions [5-9]. Cell contact and subsequent signaling are thus coupled at the apical junctions, representing the structural and functional aspects involved in the morphogenesis of multicellular organisms.

Specialized structures composed of endothelial cells, podocytes, and renal tubular cells play critical roles in glomerular and tubular functions. Genetic and biochemical studies have made important contributions to our knowledge of normal glomerular filtration and the mechanisms of proteinuria. Dysregulation of podocyte proteins is thought to play a key role in the development of the nephropathy since studies on hereditary proteinuria syndromes have led to the identification of proteins involved in the development and function of the glomerular filtration barrier [10]. Some components of the podocyte slit diaphragm are reportedly defective in humans: Nephrins, Neph-1 and Neph-2, are transmembrane proteins with extracellular IgG-like motifs, FAT-1 and FAT-2 are transmembrane proteins with extracellular cadherinlike motifs, and podocin is an integral membrane protein with its $\mathrm{N}$ - and C-terminals located intracellularly. These proteins are thus thought to form a complex that contributes to the structure of the slit diaphragm, connects the diaphragm to the intracellular actin cytoskeleton, and participates in signaling related to turnover of the glomerular filter. However, physiological regulation of their functions and pathological mechanism in causing renal disorders remain largely unknown because of the lack of suitable experimental conditions.

Studies on signalings initiated by the engagement of nectins and cadherins provide some insights into the formation of the kidney-specific apparatus and maintenance or turnover of renal cell adhesion. Protein phosphorylation mediated by c-Src and activation of Rho family small $G$ proteins are supposed to be involved in normal kidney functions through remodeling of the actin cytoskeleton. Consistently, mice lacking Rho GDI $\alpha$ show prominent proteinuria and progressive degeneration of renal epithelial cells. Here we review recent studies on the nectin and Necl systems and discuss the roles of the apical junctions in glomerular filtration and tubular function.

\section{Molecular Properties of Nectins and Necls}

All of the nectins have an extracellular region of three Ig-like domains, a transmembrane region, and a cytoplasmic tail region (fig. 1). The extracellular domain of nectins first binds to form cis-dimers on the surface of the same cells, and then promotes cell-cell contacts by forming homophilic or heterophilic trans-dimers in a calcium-independent manner. Heterophilic interactions have been detected between nectin- 2 and nectin-3, between nectin-1 and nectin-3, and also between nectin-1 and nectin-4 (fig. 1). Importantly, heterophilic trans-dimers form stronger cell-cell attachment than homophilic trans-dimers [11, 12], which actually determines the type of cell adhesion. Their cytoplasmic domains directly interact with the actin-binding protein afadin $[13,14]$ and the cell polarity protein Par-3, and indirectly interact with annexin II [15, 16], IQGAP1 [17, 18], and other actinbinding proteins. Namely, nectins play a dual role in promoting adhesion between homotypic cells and between heterotypic cells in contrast to cadherins that exclusively promote adhesion between homotypic cells.

Necls are characterized by possessing domain structures similar to those of nectins, but lack the ability to interact with afadin (fig. 1) [3, 19]. The first Ig-like domain plays an essential role in calcium-independent homophilic and heterophilic trans-interactions [20]. Each member of Necls, except for Necl-5, forms homophilic trans-dimers whereas all members form heterophilic trans-dimers with other Necl members. They also show heterophilic interaction with nectins, specific ligands, and viruses. These possible combinations of their interactions are shown (fig. 1) [8, 9]. For example, Necl-1 shows homophilic and heterophilic cell-cell adhesion activity with Necl-2, nectin-1, and nectin-3, but not with Necl-5 or nectin-2 [21]. On the other hand, Necl-5 forms homophilic cis-dimers but not homophilic trans-dimers. Necl5-based cell adhesions are not stable but easily reconstructed to the binding between Necl-5 and nectin-3 and subsequently converted to that between nectin-1 and nectin-3, suggesting the role in the quick fixing of cell contact that is programmed to achieve the remodeling process. Although Necl-5 is grouped with Necls because of the lack of ability to bind afadin [19,22], Necl-5 is phylogenetically closer to the nectin family than the Necl family [19, 23], and could be a subfamily distinct from nectins and Necls. Thus Necls form a family with more versatile functions than nectins.

Nectins are expressed ubiquitously in epithelial cells of various organs including the kidney, where they local-

Am J Nephrol 2007;27:590-604 

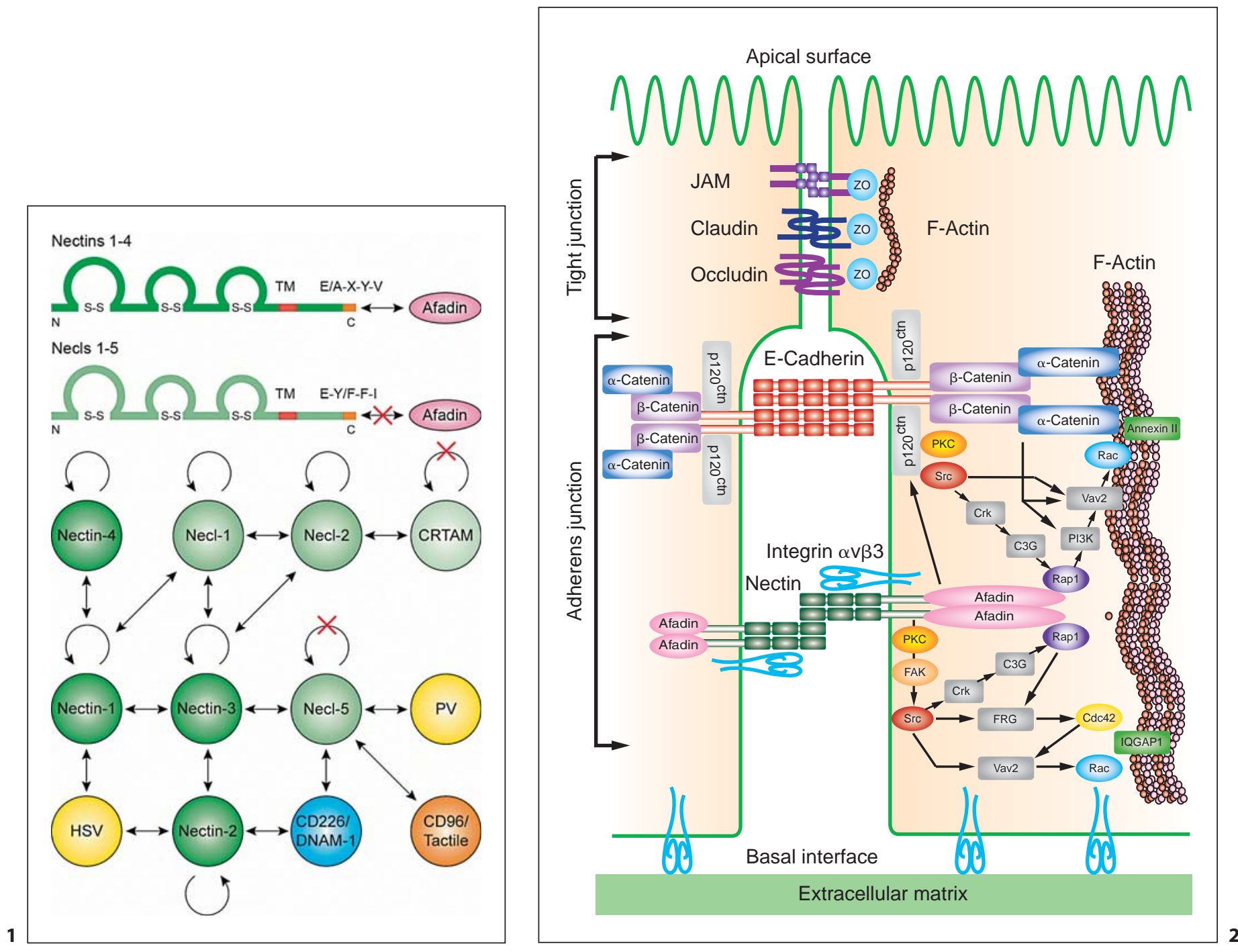

Fig. 1. Molecular structures of nectins and Necls and mode of interactions. Upper panels show the structures of nectins and Necls comprising three Ig-like extracellular domains, transmembrane domains (TM), and cytoplasmic domains. Four amino acid motifs at the C-terminus of nectins and Necls determine the affinity for binding the PDZ domain of afadin. Lower panels indicate homotypic (looped arrows) and heterotypic (double-headed arrows) interactions among nectins, Necls, herpesvirus (HSV), poliovirus (PV), and other ligands. For example, the heterotypic CRTAMNecl-2 interaction has a higher affinity than the homotypic Necl2-Necl-2 interaction, suggesting that Necl-2 preferentially binds CRTAM and CRTAM can therefore interfere with homotypic Necl-2 binding. Homotypic binding represents homophilic cellcell interaction between the same cell types whereas heterotypic interaction represents heterophilic cell-cell interaction between different cell types such as lymphocytes and epithelial cells.

Fig. 2. Signalings mediated by nectins in epithelial cells joined by the apical adhesion complex. The epithelial cytoskeleton has a denser network of actin filaments in the adherens junctions than in tight junctions. Nectin-based and E-cadherin-based cell adhesions are connected via several cytoplasmic proteins into belts of actin filaments that underlie adherens junctions. Afadin binds the tail of nectin cis-dimers as well as the actin cytoskeleton, interacting with Rap1. p120 $20^{\mathrm{ctn}}$ and $\beta$-catenin bind the tail of E-cadherin cis-dimers, and then $\alpha$-catenin binds $\beta$-catenin. Afadin and the catenins can mediate interactions to $\mathrm{ZO}$ proteins (not shown in this figure) and F-actin-binding proteins including IQGAP1 and annexin II. Formation of trans-dimers of E-cadherin causes activation of c-Src. c-Src activates Rap1 through Crk and C3G (GEF for Rap1), and then Rap1 activates Rac1 through PI3K and Vav2 (GEF for Rac1), leading to the reorganization of the actin cytoskeleton. On the other hand, nectins physically associate with integrin $\alpha v \beta 3$. c-Src also activates Racl through phosphorylation of Vav2. With the aid of integrin $\alpha v \beta 3$, formation of trans-dimers of nectins causes sequential activation of protein kinase C (PKC), focal adhesion kinase (FAK), and c-Src. c-Src activates Rap1 through Crk and C3G, activates Cdc42 through FRG (GEF for Cdc42), and activates Racl through Vav2. In addition, afadin interacts with activated Rapl and associates with p $120^{\mathrm{ctn}}$, leading to the inhibition of the endocytosis of E-cadherins. Thus, Rap1, Rac, and Cdc42 play roles in facilitating nectin and cadherin clustering through dynamic changes of the actin cytoskeleton. 
Table 1. Roles of nectins and nectin-like molecules

\begin{tabular}{|c|c|c|}
\hline & Old nomenclature & Properties \\
\hline Nectin-1 & PRR1/HveC & $\begin{array}{l}\text { Receptor for } \alpha \text {-herpesvirus entry } \\
\text { Mutation in Zlotogora-Ogur syndrome } \\
\text { Microphthalmia and other phenotypes in mice }\end{array}$ \\
\hline Nectin-2 & PRR2/HveB & $\begin{array}{l}\text { Receptor for } \alpha \text {-herpesvirus entry } \\
\text { Male-specific infertility in mice }\end{array}$ \\
\hline Nectin-3 & PRR3 & $\begin{array}{l}\text { Receptor for } \alpha \text {-herpesvirus entry } \\
\text { Microphthalmia in mice } \\
\text { Male-specific infertility in mice }\end{array}$ \\
\hline Nectin-4 & & Overexpressed in breast carcinoma \\
\hline Necl-1 & TSLL1/SynCAM3 & Morphogenesis of the brain \\
\hline Necl-2 & $\begin{array}{l}\text { RA175/IGSF4/SgIGSF } \\
\text { TSLC1/SynCAM1 }\end{array}$ & Tumor suppressor of lung carcinoma \\
\hline Necl-3 & NECL3/SynCAM2 & \\
\hline Necl-4 & TSLL2/SynCAM4 & Possible tumor suppressor \\
\hline Necl-5 & Tage4/PVR/CD155 & $\begin{array}{l}\text { Receptor for poliovirus entry } \\
\text { Overexpressed in a variety of carcinomas } \\
\text { Contact inhibition in cells in culture }\end{array}$ \\
\hline
\end{tabular}

ize to adherens junctions and are thought to play a regulatory role in cadherin-based adherens junction formation $[13,24,25]$. In contrast, Necls are expressed in a variety of cells where they localize to the leading edges of moving cells or the basolateral plasma membrane in polarized cells $[19,26]$. Therefore, Necls appear to play physiological roles except for the formation of adherens junctions, although both nectins and Necls mediate homotypic as well as heterotypic cell-cell interaction $[8,9$, 26].

\section{Biological Properties of Nectins and Necls}

\section{Nectins Recruit Adherens Junction and Tight \\ Junction Components to Establish the Apical \\ Junctions in MDCK Cells}

Nectins and cadherins participate in the organization of adherens junctions in epithelial sheets (fig. 2). Nectins are composed of four members (table 1) whereas cadherins form a large superfamily with over 80 members of classical cadherins and non-classical cadherins [27]. As the cytoplasmic tails of cadherins bind the catenin complex, those of nectins directly bind afadin as well as Par-3 $[13,28]$. Importantly, anchoring proteins such as catenins, afadin, and Par-3 cooperatively contribute to cluster

Nectin and Nectin-Like Molecules: cadherins and nectins. Thus, nectins play roles in forming mature adherens junctions that are strong yet easily remodeled.

Nectin-based cell-cell adhesions act independently and cooperate with cadherin-based cell-cell adhesions. In MDCK cells, nectins initiate cell-cell adhesion and then recruit cadherins to the nectin-based cell-cell adhesion sites to establish mature adherens junctions. Nectins need to interact with annexin II and IQGAP1 to establish adherens junctions in MDCK cells [16, 18, 29]. Nectins further promote formation of tight junctions by recruiting JAM-A, claudin-1, and occludin [30]. On the other hand, nectins are physically associated with integrin $\alpha v \beta 3$ [31] and PDGF receptor through their extracellular domains to cooperatively regulate the formation of adherens junctions in MDCK cells [31,32] and cell survival. Thus, nectins play roles for establishing apical junctional complex, as well as for promoting 'cross-talk' between cell-cell junctions and cell-matrix adhesions [9, 33-35].

\section{Signalings from Nectins Promote Apical Junction} Formation

When cells contact each other via binding of cell adhesion molecules, signals are transduced to strengthen the linkage between the apical junctions and the actin cytoskeleton. Interactions to form trans-dimers of nectins 
firstly activate c-Src. Subsequent signalings cause the activation of Rap1, Cdc42 and Rac, which promote the formation of adherens junctions mediated by the IQGAP1dependent remodeling of the actin cytoskeleton (fig. 2) $[18,36-41]$. In addition, the afadin and activated Rap1 complex interacts with $120^{\mathrm{ctn}}$ to strengthen the binding between $\mathrm{p} 120^{\mathrm{ctn}}$ and E-cadherin [42, 43]. Furthermore, the cell polarity proteins, Par-3 and Par-6, and atypical protein kinase $\mathrm{C}(\mathrm{PKC})$ that form a ternary complex could be implicated in the assembly of adherens junctions [28, $44-46]$. These cell polarity proteins and afadin could play cooperative roles in the formation of adherens junctions and tight junctions. Consequently, nectins induce elaborate protein interactions and signalings to establish mature adherens junctions in two ways: direct interactions with $\mathrm{F}$-actin-binding proteins as well as indirect organization of Cdc42- and Rac-mediated signalings (fig. 2) [9].

\section{Signalings Mediated by Afadin}

Except for the ability to link nectins to the actin cytoskeleton, afadin plays additional roles in cell survival and growth in non-epithelial cells. Afadin knockdown experiments by RNA interference show the downregulation of the phosphatidylinositol 3-kinase (PI3K)/Akt signaling in NIH3T3 cells with cell contacts. Afadin supports PDGF-induced activation of PI3K and the anti-apoptotic Akt signaling. Akt promotes cell survival by phosphorylating and thereby inactivating several pro-apoptotic proteins including BAD and Forkhead transcription factors [47]. Consistently, embryonic stem cells lacking afadin show increased apoptosis.

On the other hand, part of afadin translocates to the leading edge of NIH3T3 cells without cells contacts. The formation of leading edge structures and cell movement involve activation of Rapl and Rac mediated by PDGF signaling. Afadin binds SHP-2 tyrosine phosphatase to promote interaction between SHP-2 and PDGF receptor, as well as enhances phosphatase activity of SHP-2. Afadin appears to elaborately regulate the dephosphorylation process of PDGF receptor and thus modify the PDGF-Ras signaling. The PDGF receptor also recruits Rap1 to activate Rac1, resulting in the formation of leading edge structures and cell movement. Notably, these mechanisms are in close relation to Necl-5-mediated contact inhibition of NHI3T3 cells as described below. Afadin-mediated signalings may thus participate in the signaling process of developmental morphogenesis and remodeling of epithelial sheets.

\section{Functions of Necl-1}

Necl-1 is specifically expressed in the adult and fetal brain and in neurogenic cells $[3,21,48]$. Necl-1 binds membrane-associated guanylate kinase family members such as Dlg3/MPP3, Pals2, and CASK $[21,49]$ and modulates the reorganization of the actin cytoskeleton through protein 4.1 [23]. Dlg3/MPP3 functions to organize cellcell junctions and mediates tumor suppression [50], while Pals2 is involved in the localization of other transmembrane proteins [26]. Necl-1 is recruited to the nectin- 1 and nectin-3-based cell-cell adhesion in the process of synapse formation at puncta adherentia junctions in the hippocampus. Puncta adherentia junctions act as mechanical adhesion sites of neuronal cells, participating in part in the formation of synaptic junctions that regulate neurotransmission. After assembled to the primordial synapses, Necl-1 may be translocated to the axonal shafts where Necl-1 may function to maintain axon bundle formation [51]. Moreover, Necl-1 mediates segregation of synapses from neighboring axons, preventing neurotransmitters from diffusing and stimulating neighboring synapses [51]. Thus, the ability of Necl-1 to interact with nectin-1 and nectin-3 suggests involvement in the process of remodeling synapses in a neural activity-dependent manner $[3,8]$.

\section{Functions of Necl-2}

Necl-2 is expressed in the brain, testis, gallbladder, liver and pancreas, but not in fibroblasts or endothelial cells $[26,52]$. Necl-2 mediates homotypic and heterotypic interactions with nectin and Necl family members, thus inducing cell adhesion $[26,53,54]$. Necl-2 is also known as a tumor suppressor gene TSLC1, which inactivates tumors in nude mice [55] and is frequently inactivated in many non-small cell lung cancers (NSCLCs) $[55,56]$. Restoration of Necl-2 expression strongly suppresses the metastasis of human NSCLC cells from the spleen to the liver in nude mice [57]. Although the mechanism of tumorsuppressing activity is not fully studied, reducing Necl-2 activity may cause a disruption in cell polarity and adhesion, thus resulting in neoplastic growth (fig. 3). The cytoplasmic domain of Necl-2 contains two important motifs, a protein 4.1-binding motif at the juxtamembrane region and a PDZ-binding domain at the C-terminus, and recruits intracellular adaptors $[48,52,58]$. One of the protein 4.1 family molecules DAL-1 acts to anchor Necl-2 to the actin cytoskeleton, and plays a crucial role in the tumor suppression mediated by Necl-2 [57]. DAL-1 is shown to be downregulated in lung cancer, and restoration of DAL-1 expression to a normal level in lung cancer 


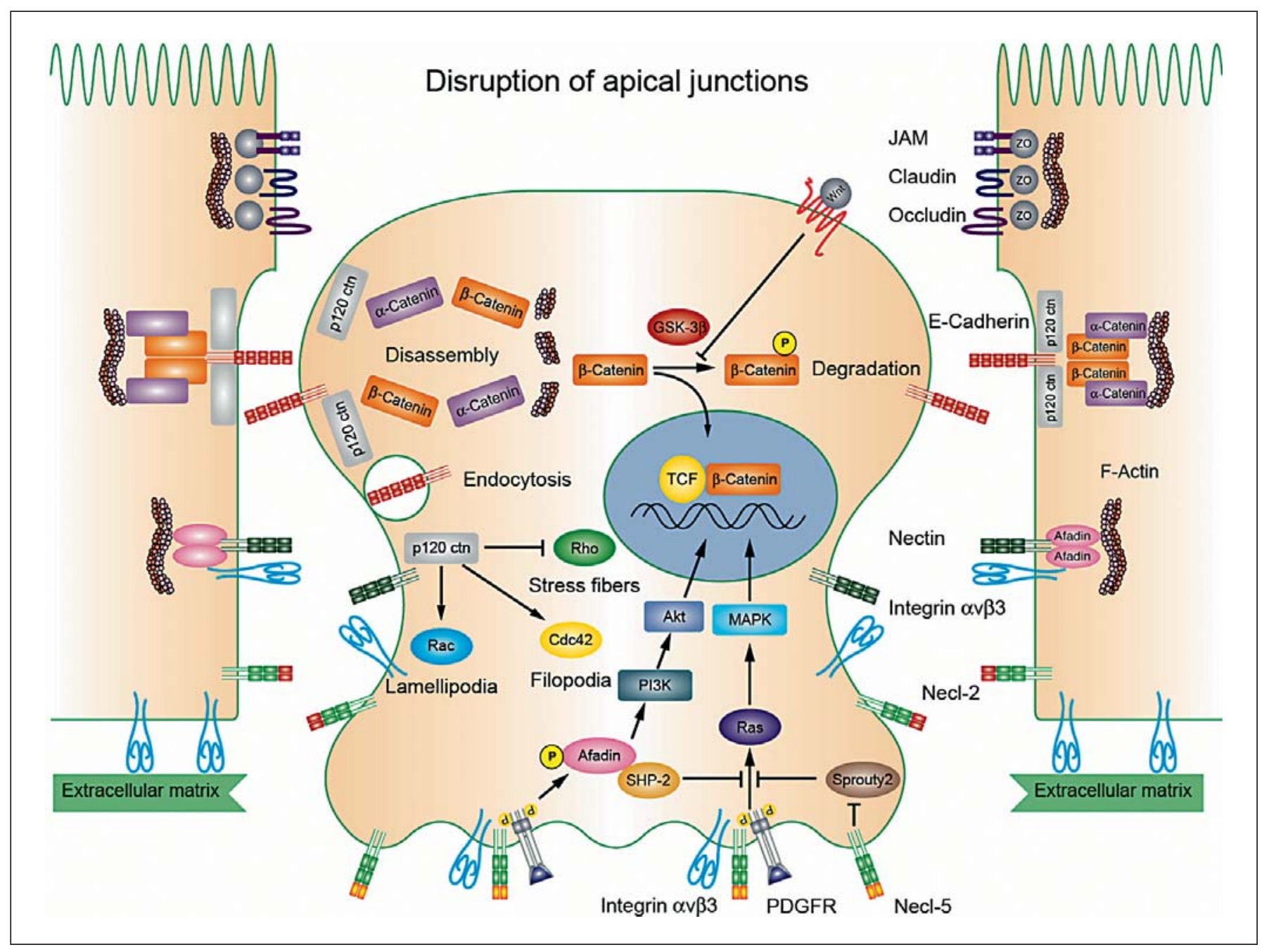

Fig. 3. Cell migration and proliferation during disruption of epithelial adherens junctions. The process of inflammation and carcinogenesis causes disruption of adherens junctions, as well as epithelial cell migration and proliferation. Dissociation of homophilic binding of E-cadherin promotes the endocytosis of E-cadherin and the disassembly of the catenins. p120 $0^{\mathrm{ctn}}$ promotes cell motility by activating Rac and Cdc42 to form lamellipodia and filopodia, and inhibits Rho activity that leads to stress-fiber formation. $\beta$-Catenin dissociated from the E-cadherin and catenin complex accumulates in the cytoplasm. Part of $\beta$-catenin translocates to the nucleus and binds to TCF to activate transcription of key genes required for survival of detached cells, while the other part of $\beta$-catenin is modified by phosphorylation and ubiqui- tination, leading to proteosome degradation. The Wnt pathway also promotes $\beta$-catenin signaling by repressing the phosphorylation of $\beta$-catenin mediated by GSK-3 $\beta$. Necl- 5 is upregulated in the solitary cells and promotes proliferation by inducing PDGFRas signaling pathway as well as by reducing inhibitory activities of Sprouty2. Afadin translocates to the leading edge of the cells where afadin binds SHP-2 and activates it to dephosphorylate the PDGF receptor, leading to the modification of PDGF-Ras signaling. Afadin also promotes anti-apoptotic PI3K/Akt signaling. Necl-2 that is normally sequestrated from immune surveillance is open to interact with CRTAM on the surface of NK cells and cytotoxic T cells. cells significantly suppressed cell growth in vitro. Colocalization of Necl-2 and DAL-1 at the cell-cell attachment site depends on the integrity of the actin cytoskeleton [57]. On the other hand, Necl-2 binds Dlg3/MPP3 and Pals2. Pals2 is known to bind Lin-7 that regulates the proper localization of Let-23 [59], the homolog of mammalian epidermal growth factor receptor that regulates vulval induction in Caenorhabditis elegans. Accordingly, Necl-2 may play tumor-suppressing roles by regulating growth factor receptors through Pals2 in mammals. 
Necl-2 binds the class-I MHC-restricted T-cell-associated molecule CRTAM [60-63], which play pivotal roles in antiviral immunity. In addition, the coordinate expression of Necl-2 and CRTAM in the cerebellum strongly suggests an important role in the function of Purkinje neurons as well [64].

\section{Functions of Necl-5}

Cell biological studies have suggested that Necl-5 functions in cell adhesion $[19,22,65,66]$, migration [6769], and proliferation [70]. Necl-5 functions as a cell adhesion molecule through trans-interaction with nectin-3 $[19,22]$. Experiments conducted in L fibroblast cells show that this trans-dimerization promotes recruitment of Ecadherin to nectin-3 in the initial stages of cell-cell contact [66]. Necl-5 colocalizes with $\alpha v \beta 3$ integrin-containing membrane microdomains [22] and is functionally associated with integrin $\alpha \mathrm{v} \beta 3$ in regulating cell motility in the absence of vitronectin [67]. Furthermore, Necl-5 promotes the transition from the $\mathrm{G} 1$ to the $\mathrm{S}$ phase of the cell cycle in NIH3T3 cells [70], accompanied by an enhancement of cell proliferation, activation of the Ras-Raf-MEKERK signaling pathway, and an upregulation of cyclin D2 and cyclin E [70]. Necl-5 is associated with Sprouty 2 that inhibits the PDGF-Ras signaling for proliferation, and thereby prevents Sprouty2 from acting as a negative growth regulator [71-73]. Necl-5 is thus proposed to play unique roles in the 'cross-talk' between cell-matrix adhesions and cell-cell junctions [9].

Necl-5 regulates contact inhibition of cell movement and proliferation [74] (fig. 4). The role of Necl-5 has recently been reviewed in detail $[8,9]$. It is believed that Necl5 makes a ternary complex with integrin $\alpha v \beta 3$ and the PDGF receptor at the leading edges of migrating cells [67]. When Necl-5 forms trans-dimers with nectin-3 at cell-cell contacts in NIH3T3 cells, Necl-5 undergoes downregulation from the cell surface, resulting in a reduction in cell proliferation and movement [75]. Since the signalings from both integrin $\alpha \mathrm{v} \beta 3$ and PDGF receptor are attenuated as a consequence of Necl-5 downregulation, Necl-5 could mediate growth arrest of cells cultured to confluence [75]. Consistently Necl-5 expression is also tightly regulated in response to changes in cell density, which is observed in NIH3T3 cells and liver epithelial cells, but not in the transformed cells [76, 77]. Hence Necl-5 explains part of the mechanisms of contact inhibition of cells in culture.

The rodent ortholog of Necl-5 (Tage4/PVR/CD155) was identified in rats as a tumor-specific marker of hepatocellular carcinoma [78-80] and colon carcinoma [81, 82], while Necl-5 is known as a poliovirus receptor/CD155

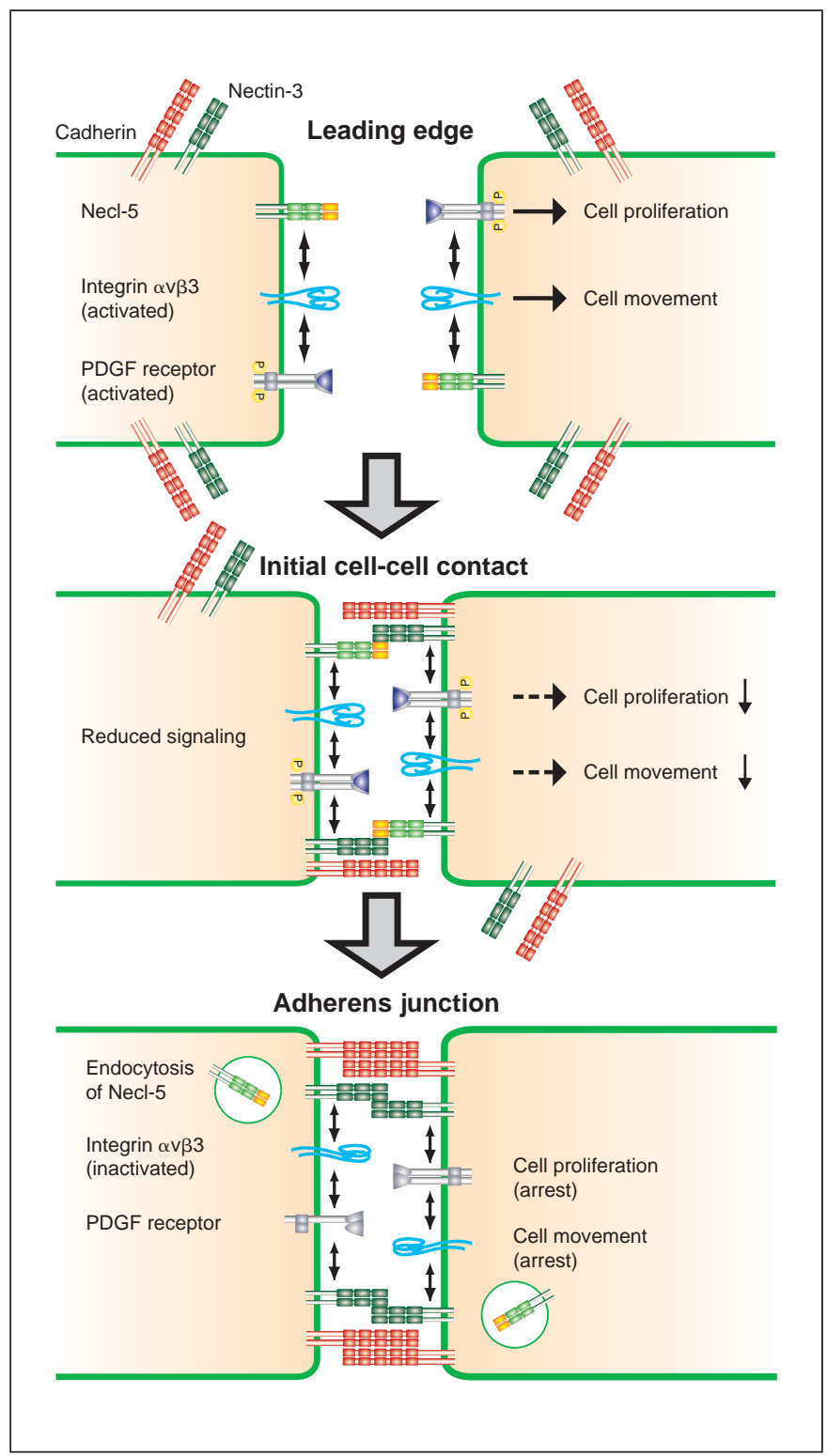

Fig. 4. Necl-5 promotes contact inhibition. At the leading edge of moving cells, Necl-5 enhances cell movement and proliferation cooperatively with activated integrin $\alpha \mathrm{v} \beta 3$ and PDGF receptor. Although initial cell contact transiently occurs through the transinteraction between nectins and Necl-5, Necl-5 is eventually incorporated to the cytosol, and then nectins and cadherins form trans-dimers during formation of the mature adherens junctions. As a consequence, integrin $\alpha v \beta 3$ and PDGF receptor stop sending signals for cell movement and proliferation. Thus, downregulation of Necl-5 coupled with inactivation of integrin $\alpha v \beta 3$ and PDGF receptor may contribute to the contact inhibition of cell movement and proliferation. 
mediating the entry of human poliovirus [83]. In contrast to the low-level expression of Necl-5 in most adult organs, Necl-5 is overexpressed in various types of cancer cells $[80,84-87]$ and a wide range of transformed cell lines [19, $80,81,84,88]$. Since Necl-5 is also expressed by hepatoblasts in the liver from embryonic day 12 to 14 [80], Necl5 appears to be an onco-fetal protein that functions during development and plays a role in the progression of cancer. Interestingly, Necl-5 acts as an immediate-early response gene during liver regeneration [77]. It remains an unanswered question, however, whether enhanced expression of Necl-5 results in disruption of adherens junctions that is one of the hallmarks of cancer cells exhibiting malignant transformation.

Necl- 5 binds DNAX accessory molecule-1 (DNAM-1/ CD226) [89] that is highly expressed in leukocytes and platelets. The interaction between DNAM-1 and Necl-5 induces the cytotoxic activities of NK cells [89], regulates monocyte transmigration through endothelial cell junctions [90], and suppresses multinucleated osteoclast formation [91]. Since DNAM-1 is also expressed in platelets, interactions of tumor cells expressing Necl-5 with platelets may favor formation of tumor emboli and subsequent metastatic events. Necl-5 is actually involved in experimental metastasis when tumor cells are injected into the tail vein and colonies in the lung are scored [92]. Although the molecular mechanism of Necl-5 involvement in these studies is not clearly defined, the ligand stimulation of Necl- 5 by DNAM-1 may trigger some physiological functions between the cells expressing each transmembrane protein, while it may suppress other cell fusion events.

\section{Knockout Studies of Nectins and Afadin}

\section{Physiological Roles of Nectins}

The phenotype of knockout mice tends to develop in selective tissues or cell lineages where the gene of interest plays an essential function that is not readily compensated by related proteins. Indeed, this is also the case for the deficiency of nectins. Knockout mice lacking each member of nectins are viable because the function of each member is redundant within the nectin family or compensated by other cell adhesion proteins. However, characteristic phenotypes develop if the interactions of nectins are unique and indispensable (table 1). One example is presented by knockout studies on nectin-1 and nectin3 indicating that heterophilic trans-interactions between nectin isoforms play important roles in morphogenesis.
Both nectin-1-deficient and nectin-3-deficient mice show microphthalmia associated with a separation of the apexapex adhesion between the pigment and non-pigment epithelia of the ciliary body [93]. Microphthalmia is a phenotype of a developmental defect of the vitreous body because of malfunction of the ciliary body. Another example is presented by knockout studies on nectin-2 and nectin-3 [94, 95]. Both nectin-2-deficient and nectin-3deficient mice show male-specific infertility and are defective in the later steps of sperm morphogenesis $[96,97]$, exhibiting distorted nuclei and abnormal distribution of mitochondria. Heterophilic interactions are essentially required between nectin- 2 on the Sertoli cell side and nectin-3 on the spermatid side. Accordingly, lacking nectin-2 or nectin-3 impairs the structure of Sertoli cellspermatid junctions by dislocalization of nectin-3 or nectin-2, respectively. It is of note that mice independently lacking two different genes show exactly the same phenotypes, which further emphasizes the significance of heterophilic interactions between nectin isoforms in vivo.

Cell-cell junctions and contacts are essential for neuronal cell migration, axon bundle formation and plasticity of synapses in the brain $[21,98]$. Nectins are involved in forming puncta adherentia junctions at synapses of a certain set of neurons [99]. Nectin-1 and nectin-3 are asymmetrically localized at the synapses of hippocampal neurons, forming heterophilic trans-dimers on the presynaptic and postsynaptic sides [100]. At the synapses in the CA3 area of the hippocampus, the number of puncta adherentia junctions is decreased in both nectin-1-deficient and nectin-3-deficient mice [101]. Furthermore, an abnormal trajectory of mossy fibers is detected at the stratum lucidum of the hippocampus in these mice, possibly as a result of impaired puncta adherentia junctions. The mechanism of abnormal trajectories is further studied in hippocampal pyramidal neurons in culture. Nectin-1 is preferentially localized in axons whereas nectin-3 is present in both axons and dendrites in these neurons. The absence of nectin-1 loosens the contacts between axons and dendritic spines, suggesting that the axon-biased localization of nectin-1 and its trans-interaction with nectin-3 is critical for the ordered association of axons and dendrites [102]. These studies clearly elucidated the roles of nectins for organization of the central nervous system.

Clinical studies on nectin-1 have revealed important roles in facial and skin morphogenesis in humans. Mutations of the nectin-1 gene cause disorders, ZlotogoraOgur syndrome and Margarita island ectodermal dysplasia, characterized by cleft lip/palate, syndactyly, mental 
retardation, and ectodermal dysplasia [103, 104]. Renal impairment has not been reported in these syndromes. The absence of nectin- 1 in mice also results in a phenotype similar to that in humans; the mice show a clear defect in skull bone development. Further studies are currently underway.

Signalings from nectins are involved in gene expression. An obvious example is loricrin, an abundant protein of the cornified cell layer of the skin. Nectin-1 activates Rapl-ERK signaling to upregulate loricrin expression in keratinocytes. Consistently, mice lacking nectin-1 show a selective reduction in loricrin protein levels of the skin [105]. Therefore, nectin-1-mediated signalings actually induce gene expression although the whole bio-informatic profiles are not elucidated.

The mechanisms underlying these phenotypes are consistent with data obtained by biochemical and cell biological studies. It is believed that knockout studies on nectins disclosed the heterophilic interactions between nectin isoforms which play important roles in the morphogenesis of the eyes, brain, skin, and testes. However, mice lacking nectins show no morphological change in the renal corpuscles and proximal and distal convoluted tubules in the kidney where multiple types of nectins are expressed. This is because the function of a nectin isoform is compensated by redundant expression of other isoforms and, by no means, because nectins play no definite role in the kidney. On the contrary, the roles of nectin associated with an elaborate back up system may be more important than those of genes whose defects instantly lead to hereditary syndromes of proteinuria. Nectins actually play crucial roles in cell adhesion and formation of junctions in MDCK cells and are involved in mouse spermatogenesis which is one of urogenital phenotypes, and these observations are not totally irrelevant to properties of normal epithelial cells in the kidney.

\section{Physiological Roles of Afadin}

Afadin is the only cytoplasmic protein known to anchor nectins to adherens junctions [14]. Afadin-deficient mice show embryonic lethality and developmental defects at stages around gastrulation (E7.5), including disorganization of the ectoderm, impaired migration of the mesoderm, loss of somites, and mixed amorphous structures derived from the ectoderm and mesoderm [106]. When afadin is conditionally inactivated using the Cre/ loxP system, the absence of afadin significantly reduces the capacity of maintaining cell-cell contacts, leading to fluid leakage or apoptosis induced by extracellular stress. Hydrocephalus is the main phenotype of mice lacking afadin, which is observed at E16.5 when the expression of Cre is driven by the nestin promoter. Ependymal cells of cerebral ventricles are disorganized and the stenosis of the aqueduct is prominent between the third and fourth ventricles. The mice lacking an isoform of atypical PKC $\lambda$ in the brain also show hydrocephalus similar to that observed with mice lacking afadin [107], suggesting that the afadin and aPKC/Par-3/Par- 6 complex may be commonly involved in the machinery required for the formation of the cerebral ventricle.

In addition, mice lacking afadin specifically in the colon are obtained by intercrossing with the villin-Cre mice. These mice show the dislocalization of nectin-2 from the apical junction to the basolateral membrane domain of the epithelial cells. Although the histological appearance of the colon epithelium appears to be mostly intact, mice lacking afadin have greater sensitivity than do the wild-type mice for apoptosis of the epithelial cells when challenged with dextran sulfate sodium. Thus, the functional integrity of the apical junctions of the colon lacking afadin may be impaired although nectins and afadin are not critically required for the morphogenesis and maintenance of the colon epithelium. It is intriguing to examine the outcome of conditional knockout of afadin in endothelial cells of the glomerulus, podocytes or tubular epithelial cells.

\section{Implications of Disrupted Adherens Junctions in Renal Disorders}

\section{Biological Significance of Rho Family Proteins}

Rho family small $\mathrm{G}$ proteins, including Rho, Rac, and $\mathrm{Cdc42}$, regulate the reorganization of the actin cytoskeleton and the integrity of adhesion complexes $[108,109]$. The roles of Rho family proteins are well documented: Rho induces stress fibers, Rac promotes lamellipodia, and Cdc42 promotes filopodia in cells in culture. As with epithelial and endothelial cells, Rac supports the formation of intercellular junctions and enhances the endothelial barrier [110-112], while Cdc42 is necessary for maintaining epithelial polarity and promoting the formation of tight junctions [113]. Activation of RhoA results in the increase in endothelial permeability [114]. Reportedly, MDCK cells overexpressing both the dominant active and negative mutants of RhoA, Rac1, and Cdc42 show disruptions in epithelial gate function and distinct morphological alterations in apical and basal filamentous actin pools [115]. These cytoskeleton-dependent activities of Rho family proteins are essential for epithelial and en- 
Fig. 5. Activation of Rho family proteins in the pathogenesis of proteinuria. The upper panel shows the glomerular filtration system that contains a fenestrated endothelium, the glomerular basement membrane, and a layer of interdigitating podocyte foot processes. The glomerulus is an epitheliallined sac invaginated by a tuft of capillaries and Bowman's space is the area between the visceral and parietal epithelial layer. The podocytes are the visceral epithelial cells that have morphologically modified shapes with the intercellular junctions composed of nephrin, Nephs, FATs and podocin. The podocyte slit diaphragm spans the filtration slit between the foot processes, slightly above the basement membrane. Sustained activation of Rho causes the disruption of endothelial cells that further enlarges fenestration whereas activation of Rac disrupts the podocyte slit diaphragm, eventually leading to massive proteinuria. The lower panel shows the transcellular and paracellular pathway of renal tubular cells that regulates reabsorption of urine materials. Rho GDI deficiency causes sustained activation of Rac and Cdc42 and the disruption of the apical junctions, as well as activation of Rho and the disruption of focal contacts, resulting in excess leakage of fluid and high-molecular weight materials through the paracellular pathway.

\section{Glomerular filtration}

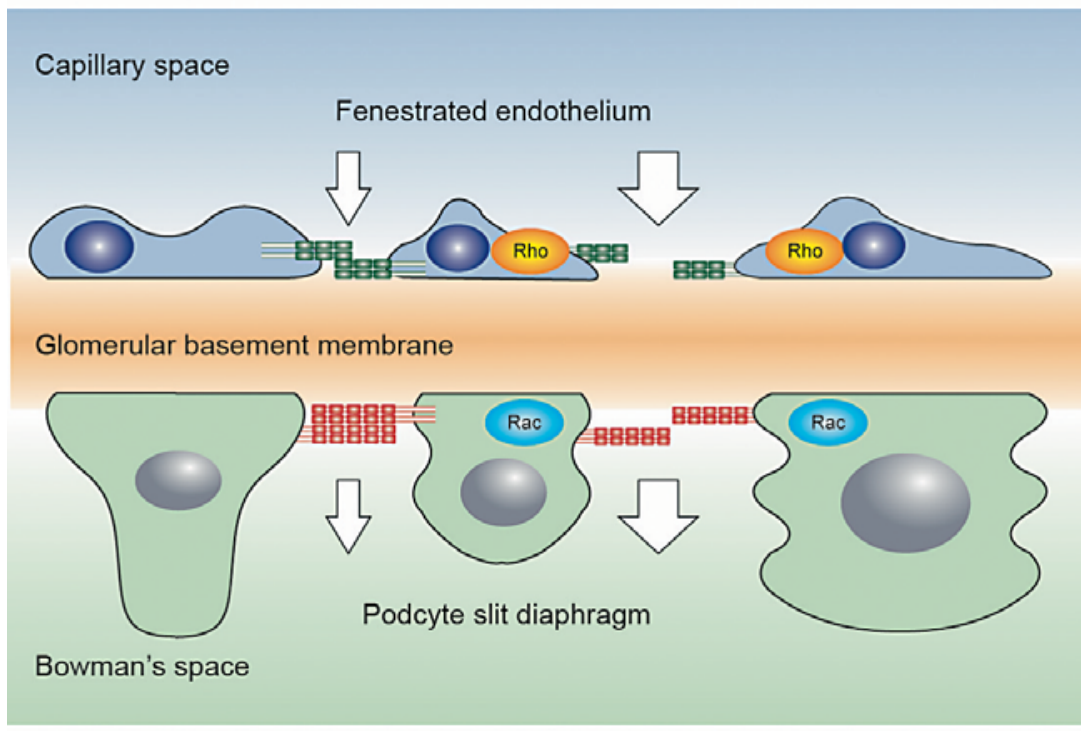

\section{Renal tubular cell}

Paracellular and transcellular pathway

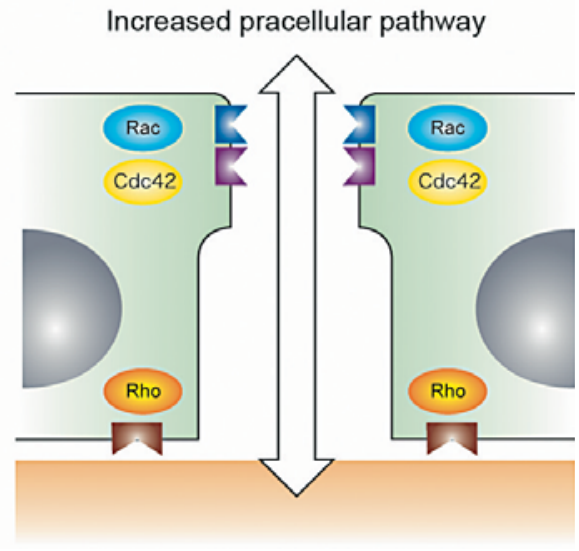

dothelial cells to assemble or disassemble cell-cell contact sites.

$\mathrm{Rac}$ and Cdc42 are activated by nectin and cadherin engagement. Activated Rac and Cdc42 are spatially confined to the outer margins in extending cell contact zones. E-Cadherin engagement recruits the Arp2/3 complex for actin assembly at the cell surface to nucleate branched actin filaments in lamellipodia [116]. Interestingly, Rho family proteins regulate both cortactin and N-WASP proteins, major actin nucleation-promoting factors for Arp2/3 activity. Whereas Rac promotes cortactin recruitment in motile cells [117], N-WASP is normally auto- inactivated but stimulates Arp2/3 complex-mediated actin polymerization when bound to activated $\mathrm{Cdc} 42$ and phosphatidylinositol-4,5-biphosphate [118]. Furthermore, formins have a domain for binding RhoA and RhoC and form dimers to promote elongation of actin filaments. These actin nucleators and their regulators thus reorganize the actin cytoskeleton in response to the Rho family protein-mediated signaling.

With the exception of Rac2, knockout studies on each member of the Rho family proteins are not very informative due to embryonic lethality. However, their regulators are good targets for gene disruption because they are not 
always essential for the viability of knockout mice. Rho family proteins serve as a molecular switch for transducing signals by exchanging the GTP- and GDP-bound states, which are regulated by guanine-nucleotide exchange proteins, GDP dissociation inhibitors (GDIs), and GTPase-activating proteins [119]. For example, a deficiency in Rho GDI $\alpha$, which is the isomer ubiquitously expressed in mouse tissues, leads to a less deleterious phenotype than a deficiency in its substrate small $G$ protein itself.

Disruption of the Rho GDI $\alpha$ gene in mice results in selective defects in the kidneys and reproductive organs [120]. Notably, Rho GDI $\alpha$-deficient mice develop prominent proteinuria mimicking nephrotic syndrome, leading to death due to renal failure within a year [119]. Histologically, degeneration of tubular epithelial cells and dilatation of distal and collecting tubules are prominent in the kidneys. The absence of Rho GDI $\alpha$ leads to the selective activation of Racl and Cdc42 in the kidneys, whereas RhoA activity is not affected [Fujita T, unpublished data]. In addition, Rho GDI $\alpha$-deficient mice show an increased permeability of pulmonary vasculature because of tight junction disruption caused by sustained activation of RhoA but not Rac1 or Cdc42 [121]. Importantly, inhibition of Rho kinase by its inhibitor Y-27632 can diminish the increased microvascular permeability in the lungs of Rho GDI $\alpha$-deficient mice. Therefore, Rho GDI $\alpha$ differentially regulates the activities of Rho family proteins in vivo. Such unbalanced regulations of Rho family proteins may lead to the junctional disassembly and disruption of the endothelial or epithelial barrier, even though the precise mechanism remains to be elucidated.

\section{Pathogenesis of Massive Proteinuria in Rho GDI $\alpha$-Deficient Mice}

Rho GDI $\alpha$ deficiency would affect the glomerulus causing proteinuria in two ways (fig. 5). One possibility is that activated Rho increases the permeability of glomerular endothelial cells possessing fenestration with a relatively large gap. Another possibility is that activated $\mathrm{Rac}$ and $\mathrm{Cdc} 42$ cause disruption of intercellular junctions between the podocytes in the glomerulus. Studies on hereditary proteinuria syndromes show that nephrin, Neph1, Neph-2, and podocin are crucial for the normal development and function of the kidneys, and that the podocyte slit diaphragm plays important roles in establishing the filtration characteristics of the glomerulus, preventing leakage of serum albumin [10]. In the rat nephritis model, exposure of visceral glomerular epithelial cells to complement initially alters the balance of Rho family proteins, with the increased RhoA activity and with the decreased Racl or Cdc42 activity [122]. Concerted activities of Rho family proteins are probably required for the physiological function of the podocyte slit diaphragm although this possibility has not been thoroughly investigated. On the other hand, Rho GDI $\alpha$-deficient mice show prominent histological changes, disruption of the apical junctions and actin cytoskeleton, which are readily detected by electron microscopy in tubular epithelial cells. Decrease in adhesion strength between renal tubular cells may be in parallel with an increase in paracellular permeability (fig. 5). Therefore, massive proteinuria in Rho GDI $\alpha$-deficient mice could be attributed to impaired glomerular filtration as well as leaky barrier function of tubular epithelial cells or the impaired reabsorption of urine.

\section{Conclusions}

Studies on nectins and Necls provide us with significant insights into the molecular mechanisms that are essential for establishing and maintaining the structure and function of adherens junctions. Adherens junctions control epithelial cell polarity while focal adhesions tend to inhibit cell migration. This balance should be elaborately regulated by 'cross-talk' between integrins and nectins or Necls. Necls form a family with more versatile functions than nectins: Necl-1 acts as an inducer of synaptic junctions in the brain, Necl-2 acts as a tumor suppressor protein and a signal for immune surveillance, and Necl-5 acts as a tumor initiator promoting cell growth. Their roles appear to be crucial for the differentiation and morphogenesis of many tissues including the kidneys.

The Rho family proteins are key regulators to understand cell adhesion biology in the kidney. However, whether or not podocin, nephrin, and related molecules initiate Rac and Cdc42 signaling remains unknown, and even such possibilities have not yet been examined. On the other hand, engagement of nectins and cadherins initiates Rac and Cdc42 signaling, resulting in reorganization of the actin cytoskeleton through actin nucleators such as formins, Arp2/3 comoplex, N-WASP, and WAVE. Thus, nectins and Necls play critical roles in establishing the apical junctions of MDCK cells although it remains largely unclear how they play roles in the kidney. They may have the potential to develop a new field of cell adhesion biology in the kidney. 
Approaches to restoring adherens junctions, cell-cell communication, and cell-matrix communication are emerging as a new therapeutic strategy for proteinuria. Aberrant immune responses or hormonal events are likely to have deleterious effects in the kidneys, leading to disruption of apical junctions of the glomerulus or renal tubular cells. Therapeutic targets might be the molecules involved in pathways affecting the adhesive properties of nectins and Necls. c-Src is a candidate because it regulates both the disruption of adherens junctions and focal- adhesion turnover [123]. Other candidates are Rho family small $\mathrm{G}$ proteins and transcriptional repressor proteins, such as snail transcriptional factor, slug, and Twist, that downregulate E-cadherin gene expression [124]. Restoring RhoA activity or antagonizing Rac activity appears to be effective to reduce the proteinuria [122]. Whether these drug therapies improve the excess remodeling of the actin cytoskeleton observed in renal injury remains unanswered.

\section{References}

1 Takeichi M: Cadherin cell adhesion recep tors as a morphogenetic regulator. Science 1991;251:1451-1455.

$\checkmark 2$ Gumbiner BM: Cell adhesion: the molecular basis of tissue architecture and morphogenesis. Cell 1996;84:345-357.

>3 Takai Y, Irie K, Shimizu K, Sakisaka T, Ikeda W: Nectins and nectin-like molecules: roles in cell adhesion, migration, and polarization. Cancer Sci 2003;94:655-667.

4 Jamora C, Fuchs E: Intercellular adhesion, signalling and the cytoskeleton. Nat Cell Biol 2002;4:E101-E108

5 Braga VM, Machesky LM, Hall A, Hotchin NA: The small GTPases Rho and Rac are required for the establishment of cadherin-dependent cell-cell contacts. J Cell Biol 1997; 137:1421-1431.

6 Ridley AJ: Rho family proteins: coordinating cell responses. Trends Cell Biol 2001;11:471477.

7 Braga VM: Cell-cell adhesion and signalling. Curr Opin Cell Biol 2002;14:546-556.

$\checkmark 8$ Sakisaka T, Takai Y: Biology and pathology of nectins and nectin-like molecules. Curr Opin Cell Biol 2004;16:513-521.

$\checkmark$ Ogita H, Takai Y: Nectins and nectin-like molecules: roles in cell adhesion, polarization, movement, and proliferation. IUBMB Life 2006;58:334-343.

-10 Tryggvason K, Patrakka J, Wartiovaara J: Hereditary proteinuria syndromes and mechanisms of proteinuria. N Engl J Med 2006;354:1387-1401.

11 Martinez-Rico C, Pincet F, Perez E, Thiery JP, Shimizu K, Takai Y, Dufour S: Separation force measurements reveal different types of modulation of E-cadherin-based adhesion by nectin-1 and -3 . J Biol Chem 2005;280: 4753-4760.

12 Satoh-Horikawa K, Nakanishi H, Takahashi K, Miyahara M, Nishimura M, Tachibana K, Mizoguchi A, Takai Y: Nectin-3, a new member of immunoglobulin-like cell adhesion molecules that shows homophilic and heterophilic cell-cell adhesion activities. J Biol Chem 2000;275:10291-10299.
13 Takahashi K, Nakanishi H, Miyahara M, Mandai K, Satoh K, Satoh A, Nishioka H, Aoki J, Nomoto A, Mizoguchi A, Takai Y: Nectin/PRR: an immunoglobulin-like cell adhesion molecule recruited to cadherinbased adherens junctions through interaction with Afadin, a PDZ domain-containing protein. J Cell Biol 1999;145:539-549.

14 Takai Y, Nakanishi H: Nectin and afadin: novel organizers of intercellular junctions. J Cell Sci 2003;116:17-27.

15 Gerke V, Moss SE: Annexins: from structure to function. Physiol Rev 2002;82:331-371.

16 Yamada A, Irie K, Hirota T, Ooshio T, Fukuhara $\mathrm{A}$, Takai $\mathrm{T}$ : Involvement of the annexin II-S100A10 complex in the formation of Ecadherin-based adherens junctions in $\mathrm{Ma}$ din-Darby canine kidney cells. J Biol Chem 2005;280:6016-6027.

17 Noritake J, Watanabe T, Sato K, Wang S, Kaibuchi K: IQGAP1: a key regulator of adhesion and migration. J Cell Sci 2005;118: 2085-2092.

18 Katata T, Irie K, Fukuhara A, Kawakatsu T, Yamada A, Shimizu K, Takai Y: Involvement of nectin in the localization of IQGAP1 at the cell-cell adhesion sites through the actin cytoskeleton in Madin-Darby canine kidney cells. Oncogene 2003;22:2097-2109.

19 Ikeda W, Kakunaga S, Itoh S, Shingai T, Takekuni K, Satoh K, Inoue Y, Hamaguchi A, Morimoto K, Takeuchi M, Imai T, Takai Y: Tage4/Nectin-like molecule-5 heterophilically trans-interacts with cell adhesion molecule Nectin-3 and enhances cell migration. J Biol Chem 2003;278:28167-28172.

20 Dong X, Xu F, Gong Y, Gao J, Lin P, Chen T, Peng Y, Qiang B, Yuan J, Peng X, Rao Z: Crystal structure of the $\mathrm{V}$ domain of human Nectin-like molecule-1/Syncam3/Tsll1/Igsf4b, a neural tissue-specific immunoglobulin-like cell-cell adhesion molecule. J Biol Chem 2006;281:10610-10617.
21 Kakunaga S, Ikeda W, Itoh S, Deguchi-Tawarada M, Ohtsuka T, Mizoguchi A, Takai Y: Nectin-like molecule-1/TSLL1/SynCAM3: a neural tissue-specific immunoglobulinlike cell-cell adhesion molecule localizing at non-junctional contact sites of presynaptic nerve terminals, axons and glia cell processes. J Cell Sci 2005;118:1267-1277.

22 Mueller S, Wimmer E: Recruitment of nectin-3 to cell-cell junctions through transheterophilic interaction with CD155, a vitronectin and poliovirus receptor that localizes to alpha(v)beta3 integrin-containing membrane microdomains. J Biol Chem 2003;278: 31251-31260.

23 Zhou Y, Du G, Hu X, Yu S, Liu Y, Xu Y, Huang X, Liu J, Yin B, Fan M, Peng X, Qiang B, Yuan $\mathrm{J}$ : Nectin-like molecule 1 is a protein $4.1 \mathrm{~N}$ associated protein and recruits protein $4.1 \mathrm{~N}$ from cytoplasm to the plasma membrane. Biochim Biophys Acta 2005;1669:142-154.

24 Honda T, Shimizu K, Fukuhara A, Irie K, Takai Y: Regulation by nectin of the velocity of the formation of adherens junctions and tight junctions. Biochem Biophys Res Commun 2003;306:104-109.

25 Honda T, Shimizu K, Kawakatsu T, Yasumi M, Shingai T, Fukuhara A, Ozaki-Kuroda K, Irie K, Nakanishi H, Takai Y: Antagonistic and agonistic effects of an extracellular fragment of nectin on formation of E-cadherinbased cell-cell adhesion. Genes Cells 2003;8: 51-63.

26 Shingai T, Ikeda W, Kakunaga S, Morimoto K, Takekuni K, Itoh S, Satoh K, Takeuchi M, Imai T, Monden M, Takai Y: Implications of nectin-like molecule-2/IGSF4/ RA175/SgIGSF/TSLC1/SynCAM1 in cellcell adhesion and transmembrane protein localization in epithelial cells. J Biol Chem 2003;278:35421-35427.

27 Yagi T, Takeichi M: Cadherin superfamily genes: functions, genomic organization, and neurologic diversity. Genes Dev 2000;14: 1169-1180. 
-28 Takekuni K, Ikeda W, Fujito T, Morimoto K, Takeuchi M, Monden M, Takai Y: Direct binding of cell polarity protein PAR-3 to cellcell adhesion molecule nectin at neuroepithelial cells of developing mouse. J Biol Chem 2003;278:5497-5500.

-29 Yamada A, Fujita N, Sato T, Okamoto R, Ooshio T, Hirota T, Morimoto K, Irie K, Takai Y: Requirement of nectin, but not cadherin, for formation of claudin-based tight junctions in annexin II-knockdown MDCK cells. Oncogene 2006;25:5085-5102.

-30 Fukuhara A, Irie K, Nakanishi H, Takekuni K, Kawakatsu T, Yamada A, Katata T, Honda T, Sato T, Shimizu K, Ozaki H, Horiuchi H, Kita T, Takai Y: Involvement of nectin in the localization of junctional adhesion molecule at tight junctions. Oncogene 2002;21:76427655.

-31 Sakamoto Y, Ogita H, Hirota T, Kawakatsu T, Fukuyama T, Yasumi M, Kanzaki N, Ozaki M, Takai Y: Interaction of integrin alpha(v)beta3 with nectin. Implication in cross-talk between cell-matrix and cell-cell junctions. J Biol Chem 2006;281:1963119644.

-32 Ozaki M, Ogita H, Takai Y: Involvement of integrin-induced activation of protein kinase $\mathrm{C}$ in the formation of adherens junctions. Genes Cells 2007;12:651-662.

33 Pignatelli M: Integrins, cadherins, and catenins: molecular cross-talk in cancer cells. J Pathol 1998;186:1-2.

-34 Siu MK, Cheng CY: Dynamic cross-talk between cells and the extracellular matrix in the testis. Bioessays 2004;26:978-992.

-35 Geiger B, Bershadsky A, Pankov R, Yamada KM: Transmembrane crosstalk between the extracellular matrix-cytoskeleton crosstalk. Nat Rev Mol Cell Biol 2001;2:793-805.

\$6 Fukuhara A, Shimizu K, Kawakatsu T, Fukuhara T, Takai Y: Involvement of nectin-activated Cdc42 small G protein in organization of adherens and tight junctions in Madin-Darby canine kidney cells. J Biol Chem 2003;278:51885-51893.

-37 Fukuhara T, Shimizu K, Kawakatsu T, Fukuyama T, Minami Y, Honda T, Hoshino T, Yamada T, Ogita H, Okada M, Takai Y: Activation of $\mathrm{Cdc} 42$ by trans-interactions of the cell adhesion molecules nectins through cSrc and Cdc42-GEF FRG. J Cell Biol 2004; 166:393-405.

- 38 Izumi G, Sakisaka T, Baba T, Tanaka S, Morimoto K, Takai Y: Endocytosis of E-cadherin regulated by $\mathrm{Rac}$ and $\mathrm{Cdc} 42$ small $\mathrm{G}$ proteins through IQGAP1 and actin filaments. J Cell Biol 2004; 166:237-248.

- 39 Kawakatsu T, Ogita H, Fukuhara T, Fukuyama T, Minami Y, Shimizu K, Takai Y: Vav2 as a Rac-GDP/GTP exchange factor responsible for the nectin-induced, c-Src- and Cdc42-mediated activation of Rac. J Biol Chem 2005;280:4940-4947.

40 Shimizu K, Takai Y: Roles of the intercellular adhesion molecule nectin in intracellular signaling. J Biochem 2003;134:631-636.
41 Fukuyama T, Ogita H, Kawakatsu T, Fukuhara T, Yamada T, Sato T, Shimizu K, Nakamura T, Matsuda M, Takai Y: Involvement of the c-Src-Crk-C3G-Rapl signaling in the nectin-induced activation of $\mathrm{Cdc} 42$ and formation of adherens junctions. J Biol Chem 2005;280:815-825.

42 Sato T, Fujita N, Yamada A, Ooshio T, Okamoto R, Irie K, Takai Y: Regulation of the assembly and adhesion activity of E-cadherin by nectin and afadin for the formation of adherens junctions in Madin-Darby canine kidney cells. J Biol Chem 2006;281: 5288-5299.

43 Hoshino T, Sakisaka T, Baba T, Yamada T, Kimura T, Takai Y: Regulation of E-cadherin endocytosis by nectin through afadin, Rap1, and p120ctn. J Biol Chem 2005;280:2409524103.

44 Ohno S: Intercellular junctions and cellular polarity: the PAR-aPKC complex, a conserved core cassette playing fundamental roles in cell polarity. Curr Opin Cell Biol 2001;13:641-648.

45 Mizuno K, Suzuki A, Hirose T, Kitamura K, Kutsuzawa K, Futaki M, Amano Y, Ohno S: Self-association of PAR-3-mediated by the conserved $\mathrm{N}$-terminal domain contributes to the development of epithelial tight junctions. J Biol Chem 2003;278:31240-31250.

46 Ooshio T, Fujita N, Yamada A, Sato T, Kitagawa Y, Okamoto R, Nakata S, Miki A, Irie K, Takai Y: Cooperative roles of Par-3 and afadin in the formation of adherens and tight junctions. J Cell Sci 2007;120:2352-2365.

47 Cully M, You H, Levine AJ, Mak TW: Beyond PTEN mutations: the PI3K pathway as an integrator of multiple inputs during tumorigenesis. Nat Rev Cancer 2006;6:184-192.

48 Fukuhara H, Kuramochi M, Nobukuni T, Fukami T, Saino M, Maruyama T, Nomura S, Sekiya T, Murakami Y: Isolation of the TSLL1 and TSLL2 genes, members of the tumor suppressor TSLC1 gene family encoding transmembrane proteins. Oncogene 2001; 20:5401-5407.

49 Smith SA, Holik P, Stevens J, Mazoyer S, Melis $\mathrm{R}$, Williams B, White R, Albertsen H: Isolation of a gene (DLG3) encoding a second member of the discs-large family on chromosome 17q12-q21. Genomics 1996;31:145-150.

50 Fukuhara H, Masuda M, Yageta M, Fukami T, Kuramochi M, Maruyama T, Kitamura T, Murakami Y: Association of a lung tumor suppressor TSLC1 with MPP3, a human homologue of Drosophila tumor suppressor Dlg. Oncogene 2003;22:6160-6165.

51 Irie K, Shimizu K, Sakisaka T, Ikeda W, Takai Y: Roles and modes of action of nectins in cell-cell adhesion. Semin Cell Dev Biol 2004; 15:643-656.

52 Fukami T, Satoh H, Fujita E, Maruyama T, Fukuhara H, Kuramochi M, Takamoto S, Momoi T, Murakami Y: Identification of the Tslcl gene, a mouse orthologue of the human tumor suppressor TSLC1 gene. Gene 2002; 295:7-12.
53 Biederer T, Sara Y, Mozhayeva M, Atasoy D, Liu X, Kavalali ET, Sudhof TC: SynCAM, a synaptic adhesion molecule that drives synapse assembly. Science 2002;297:1525-1531.

54 Masuda M, Yageta M, Fukuhara H, Kuramochi M, Maruyama T, Nomoto A, Murakami Y: The tumor suppressor protein TSLC1 is involved in cell-cell adhesion. J Biol Chem 2002;277:31014-31019.

55 Kuramochi M, Fukuhara H, Nobukuni T, Kanbe T, Maruyama T, Ghosh HP, Pletcher M, Isomura M, Onizuka M, Kitamura T, Sekiya T, Reeves RH, Murakami Y: TSLC1 is a tumor-suppressor gene in human nonsmall-cell lung cancer. Nat Genet 2001;27: 427-430.

56 Fukuhara H, Kuramochi M, Fukami T, Kasahara K, Furuhata M, Nobukuni T, Maruyama T, Isogai K, Sekiya T, Shuin T, Kitamura T, Reeves RH, Murakami Y: Promoter methylation of TSLC1 and tumor suppression by its gene product in human prostate cancer. Jpn J Cancer Res. 2002;93:605-609.

57 Yageta M, Kuramochi M, Masuda M, Fukami T, Fukuhara H, Maruyama T, Shibuya M, Murakami Y: Direct association of TSLC1 and DAL-1, two distinct tumor suppressor proteins in lung cancer. Cancer Res 2002;62: 5129-5133.

-58 Songyang Z, Fanning AS, Fu C, Xu J, Marfatia SM, Chishti AH, Crompton A, Chan AC, Anderson JM, Cantley LC: Recognition of unique carboxyl-terminal motifs by distinct PDZ domains. Science 1997;275:73-77.

59 Kaech SM, Whitfield CW, Kim SK: The LIN2/LIN-7/LIN-10 complex mediates basolateral membrane localization of the C. elegans EGF receptor LET-23 in vulval epithelial cells. Cell 1998;94:761-771.

60 Galibert L, Diemer GS, Liu Z, Johnson RS, Smith JL, Walzer T, Comeau MR, Rauch CT, Wolfson MF, Sorensen RA, Van der Vuurst de Vries AR, Branstetter DG, Koelling RM, Scholler J, Fanslow WC, Baum PR, Derry JM, Yan W: Nectin-like protein 2 defines a subset of T-cell zone dendritic cells and is a ligand for class-I restricted T-cell associated molecule. J Biol Chem 2005;280:21955-21964.

61 Arase N, Takeuchi A, Unno M, Hirano S, Yokosuka T, Arase H, Saito T: Heterotypic interaction of CRTAM with $\mathrm{Necl} 2$ induces cell adhesion on activated NK cells and CD8+ T cells. Int Immunol 2005; 17:1227-1237.

62 Kennedy J, Vicari AP, Saylor V, Zurawski SM, Copeland NG, Gilbert DJ, Jenkins NA, Zlotnik A: A molecular analysis of NKT cells: identification of a class-I restricted $\mathrm{T}$ cell-associated molecule (CRTAM). J Leukoc Biol 2000;67:725-734.

63 Boles KS, Barchet W, Diacovo T, Cella M, Colonna M: The tumor suppressor TSLC1/ NECL-2 triggers NK-cell and CD8+ T-cell responses through the cell-surface receptor CRTAM. Blood 2005;106:779-786. 
64 Patino-Lopez G, Hevezi P, Lee J, Willhite D, Verge GM, Lechner SM, Ortiz-Navarrete V, Zlotnik A: Human class-I restricted T cell associated molecule is highly expressed in the cerebellum and is a marker for activated NKT and CD8+ T lymphocytes. J Neuroimmunol 2006;171:145-155.

-65 Lange R, Peng X, Wimmer E, Lipp M, Bernhardt G: The poliovirus receptor CD155 mediates cell-to-matrix contacts by specifically binding to vitronectin. Virology 2001;285: 218-227.

66 Sato T, Irie K, Ooshio T, Ikeda W, Takai Y: Involvement of heterophilic trans-interaction of Necl-5/Tage4/PVR/CD155 with nectin-3 in formation of nectin- and cadherinbased adherens junctions. Genes Cells 2004; 9:791-799.

67 Ikeda W, Kakunaga S, Takekuni K, Shingai T, Satoh K, Morimoto K, Takeuchi M, Imai T, Takai Y: Nectin-like molecule-5/Tage4 enhances cell migration in an integrin-dependent, Nectin-3-independent manner. J Biol Chem 2004;279:18015-18025.

68 Oda T, Ohka S, Nomoto A: Ligand stimulation of CD155alpha inhibits cell adhesion and enhances cell migration in fibroblasts. Biochem Biophys Res Commun 2004;319: 1253-1264.

-69 Sloan KE, Eustace BK, Stewart JK, Zehetmeier C, Torella C, Simeone M, Roy JE, Unger C, Louis DN, Ilag LL, Jay DG: CD155/PVR plays a key role in cell motility during tumor cell invasion and migration. BMC Cancer 2004; 4:73.

-70 Kakunaga S, Ikeda W, Shingai T, Fujito T, Yamada A, Minami Y, Imai T, Takai Y: Enhancement of serum- and platelet-derived growth factor-induced cell proliferation by Necl-5/Tage4/poliovirus receptor/CD155 through the Ras-Raf-MEK-ERK signaling. J Biol Chem 2004;279:36419-36425.

-71 Hanafusa H, Torii S, Yasunaga T, Nishida E: Sproutyl and Sprouty2 provide a control mechanism for the Ras/MAPK signalling pathway. Nat Cell Biol 2002;4:850-858.

72 Kim HJ, Bar-Sagi D: Modulation of signalling by Sprouty: a developing story. Nat Rev Mol Cell Biol 2004;5:441-450.

-73 Kajita M, Ikeda W, Tamaru Y, Takai Y: Regulation of platelet-derived growth factor-induced Ras signaling by poliovirus receptor Necl-5 and negative growth regulator Sprouty2. Genes Cells 2007;12:345-357.

74 Fisher HW, Yeh J: Contact inhibition in colony formation. Science 1967;155:581-582.

-75 Fujito T, Ikeda W, Kakunaga S, Minami Y, Kajita M, Sakamoto Y, Monden M, Takai Y: Inhibition of cell movement and proliferation by cell-cell contact-induced interaction of Necl-5 with nectin-3. J Cell Biol 2005;171: 165-173.
Minami Y, Ikeda W, Kajita M, Fujito T, Monden M, Takai Y: Involvement of up-regulated Necl-5/Tage4/PVR/CD155 in the loss of contact inhibition in transformed NIH3T3 cells. Biochem Biophys Res Commun 2007;352: 856-860.

77 Erickson BM, Thompson NL, Hixson DC: Tightly regulated induction of the adhesion molecule Necl-5/CD155 during rat liver regeneration and acute liver injury. Hepatology $2006 ; 43: 325-334$.

78 Hixson DC, McEntire KD, Obrink B: Alterations in the expression of a hepatocyte cell adhesion molecule by transplantable rat hepatocellular carcinomas. Cancer Res 1985; 45:3742-3749.

79 Faris RA, McEntire KD, Thompson NL, Hixson DC: Identification and characterization of a rat hepatic oncofetal membrane glycoprotein. Cancer Res 1990;50:4755-4763.

80 Lim YP, Fowler LC, Hixson DC, Wehbe T, Thompson NL: TuAg.1 is the liver isoform of the rat colon tumor-associated antigen pE4 and a member of the immunoglobulin-like supergene family. Cancer Res 1996;56:39343940.

81 Douillard JY, Laborda J, Burg C, Ridge J, Levenbook I, Blottiere H, Sela B, Hoffman T: Monoclonal antibodies to a rat colon carcinoma: model for monoclonal antibody therapy of solid tumors. Cancer Res 1989;49: 687-692.

82 Chadeneau C, Denis MG, Blottiere HM, Gregoire M, Douillard JY, Me-flah K: Characterization, isolation and amino terminal sequencing of a rat colon carcinoma-associated antigen. Int J Cancer 1991;47:903-908.

83 Mendelsohn CL, Wimmer E, Racaniello VR: Cellular receptor for poliovirus: molecular cloning, nucleotide sequence, and expression of a new member of the immunoglobulin superfamily. Cell 1989;56:855-865.

84 Chadeneau C, LeMoullac B, Denis MG: A novel member of the immunoglobulin gene superfamily expressed in rat carcinoma cell lines. J Biol Chem 1994;269:15601-15605.

85 Masson D, Jarry A, Baury B, Blanchardie P, Laboisse C, Lustenberger P, Denis MG: Overexpression of the CD155 gene in human colorectal carcinoma. Gut 2001;49:236-240.

86 Gromeier M, Lachmann S, Rosenfeld MR, Gutin PH, Wimmer E: Intergeneric poliovirus recombinants for the treatment of malignant glioma. Proc Natl Acad Sci USA 2000; 97:6803-6808

87 Chadeneau C, LeCabellec M, LeMoullac B, Meflah K, Denis MG: Over-expression of a novel member of the immunoglobulin superfamily in Min mouse intestinal adenomas. Int J Cancer 1996;68:817-821.

88 Koike S, Horie H, Ise I, Okitsu A, Yoshida M, Iizuka N, Takeuchi K, Takegami T, Nomoto A: The poliovirus receptor protein is produced both as membrane-bound and secreted forms. EMBO J 1990;9:3217-3224.
89 Bottino C, Castriconi R, Pende D, Rivera P, Nanni M, Carnemolla B, Cantoni C, Grassi J, Marcenaro S, Reymond N, Vitale M, Moretta L, Lopez M, Moretta A: Identification of PVR (CD155) and Nectin-2 (CD112) as cell surface ligands for the human DNAM1 (CD226) activating molecule. J Exp Med 2003; 198:557-567.

90 Reymond N, Imbert AM, Devilard E, Fabre S, Chabannon C, Xerri L, Farnarier C, Cantoni C, Bottino C, Moretta A, Dubreuil P, Lopez M: DNAM-1 and PVR regulate monocyte migration through endothelial junctions. J Exp Med 2004;199:1331-1341.

91 Kakehi S, Nakahama KI, Morita I: Expression and possible role of PVR/CD155/Necl-5 in osteoclastogenesis. Mol Cell Biochem 2007;301:209-217.

92 Morimoto K, Satoh-Yamaguchi K, Hamaguchi A, Inoue Y, Takeuchi M, Okada M, Ikeda W, Takai Y, Imai T: Interaction of cancer cells with platelets mediated by Necl-5/poliovirus receptor enhances cancer cell metastasis to the lungs. Oncogene, in press.

93 Inagaki M, Irie K, Ishizaki H, Tanaka-Okamoto M, Morimoto K, Inoue E, Ohtsuka T, Miyoshi J, Takai Y: Roles of cell-adhesion molecules nectin 1 and nectin 3 in ciliary body development. Development 2005;132: 1525-1537.

94 Mueller S, Rosenquist TA, Takai Y, Bronson RA, Wimmer E: Loss of nectin-2 at Sertolispermatid junctions leads to male infertility and correlates with severe spermatozoan head and midpiece malformation, impaired binding to the zona pellucida, and oocyte penetration. Biol Reprod 2003;69:13301340.

95 Inagaki M, Irie K, Ishizaki H, Tanaka-Okamoto M, Miyoshi J, Takai Y: Role of cell adhesion molecule nectin-3 in spermatid development. Genes Cells 2006;11:1125-1132.

96 Ozaki-Kuroda K, Nakanishi H, Ohta H, Tanaka H, Kurihara H, Mueller S, Irie K, Ikeda W, Sasaki T, Wimmer E, Nishimune Y, Takai Y: Nectin couples cell-cell adhesion and the actin scaffold at heterotypic testicular junctions. Curr Biol 2002;12:1145-1150.

97 Bouchard MJ, Dong Y, McDermott BM Jr, Lam DH, Brown KR, Shelanski M, Bellve AR, Racaniello VR: Defects in nuclear and cytoskeletal morphology and mitochondrial localization in spermatozoa of mice lacking nectin-2, a component of cell-cell adherens junctions. Mol Cell Biol 2000;20:28652873.

98 Redies C, Takeichi M: Cadherins in the developing central nervous system: an adhesive code for segmental and functional subdivisions. Dev Biol 1996;180:413-423.

99 Nakanishi H, Takai Y: Roles of nectins in cell adhesion, migration and polarization. Biol Chem 2004;385:885-892. 
100 Mizoguchi A, Nakanishi H, Kimura K, Matsubara K, Ozaki-Kuroda K, Katata T, Honda T, Kiyohara Y, Heo K, Higashi M, Tsutsumi T, Sonoda S, Ide C, Takai Y: Nectin: an adhesion molecule involved in formation of synapses. J Cell Biol 2002;156: $555-565$.

101 Honda T, Sakisaka T, Yamada T, Kumazawa N, Hoshino T, Kajita M, Kayahara T, Ishizaki H, Tanaka-Okamoto M, Mizoguchi A, Manabe T, Miyoshi J, Takai Y: Involvement of nectins in the formation of puncta adherentia junctions and the mossy fiber trajectory in the mouse hippocampus. Mol Cell Neurosci 2006;31:315-325.

102 Togashi H, Miyoshi J, Honda T, Sakisaka T, Takai Y, Takeichi M: Interneurite affinity is regulated by heterophilic nectin interactions in concert with the cadherin machinery. J Cell Biol 2006;174:141-151.

103 Suzuki K, Hu D, Bustos T, Zlotogora J, Richieri-Costa A, Helms JA, Spritz RA: Mutations of PVRL1, encoding a cell-cell adhesion molecule/herpesvirus receptor, in cleft lip/palate-ectodermal dysplasia. Nat Genet 2000;25:427-430.

104 Sozen MA, Suzuki K, Tolarova MM, Bustos T, Fernandez Iglesias JE, Spritz RA: Mutation of PVRL1 is associated with sporadic, non-syndromic cleft lip/palate in northern Venezuela. Nat Genet 2001;29:141-142.

105 Wakamatsu K, Ogita H, Okabe N, Irie K, Tanaka-Okamoto $\mathrm{M}$, Ishizaki $\mathrm{H}$, IshidaYamamoto A, Iizuka H, Miyoshi J, Takai Y: Up-regulation of loricrin expression by cell adhesion molecule nectin-1 through Rap1ERK signaling in keratinocytes. J Biol Chem 2007;282:18173-18181.

106 Ikeda W, Nakanishi H, Miyoshi J, Mandai K, Ishizaki H, Tanaka M, Togawa A, Takahashi K, Nishioka H, Yoshida H, Mizoguchi A, Nishikawa S, Takai Y: Afadin: A key molecule essential for structural organization of cell-cell junctions of polarized epithelia during embryogenesis. J Cell Biol 1999;146: 1117-1132.
107 Imai F, Hirai S, Akimoto K, Koyama H, Miyata T, Ogawa M, Noguchi S, Sasaoka T, Noda $\mathrm{T}$, Ohno S: Inactivation of aPKClambda results in the loss of adherens junctions in neuroepithelial cells without affecting neurogenesis in mouse neocortex. Development 2006;133:1735-1744.

108 Etienne-Manneville S, Hall A: Rho GTPases in cell biology. Nature 2002;420:629635.

109 Raftopoulou M, Hall A: Cell migration: 11 Rho GTPases lead the way. Dev Biol 2004; 265:23-32.

110 van Leeuwen FN, van Delft S, Kain HE, van der Kammen RA, Collard JG: Rac regulates phosphorylation of the myosin-II heavy chain, actinomyosin disassembly and cell spreading. Nat Cell Biol 1999;1:242-248.

$\checkmark 11$ Wojciak-Stothard B, Potempa S, Eichholtz T, Ridley AJ: Rho and Rac but not Cdc42 regulate endothelial cell permeability. J Cell Sci 2001;114:1343-1355.

112 van Wetering S, van Buul JD, Quik S, Mul FP, Anthony EC, ten Klooster JP, Collard JG, Hordijk P: Reactive oxygen species me- 1 diate Rac-induced loss of cell-cell adhesion in primary human endothelial cells. J Cell Sci 2002;115:1837-1846.

$\checkmark 113$ Kouklis P, Konstantoulaki M, Vogel S, Broman M, Malik AB: Cdc42 regulates the restoration of endothelial barrier function. Circ Res 2004;94:159-166.

$\checkmark 114$ van Nieuw Amerongen GP, van Delft S, Vermeer MA, Collard JG, van Hinsbergh VW: Activation of RhoA by thrombin in endothelial hyperpermeability: role of Rho kinase and protein tyrosine kinases. Circ Res 2000;87:335-340.

115 Bruewer M, Hopkins AM, Hobert ME, Cdc42 exert distinct effects on epithelial barrier via selective structural and biochemical modulation of junctional proteins and F-actin. Am J Physiol Cell Physiol 2004; 287:C327-C335.
Kovacs EM, Goodwin M, Ali RG, Paterson $\mathrm{AD}$, Yap AS: Cadherin-directed actin assembly: E-cadherin physically associates with the Arp2/3 complex to direct actin assembly in nascent adhesive contacts. Curr Biol 2002;12:379-382.

17 Weed SA, Du Y, Parsons JT: Translocation of cortactin to the cell periphery is mediated by the small GTPase Racl. J Cell Sci 1998;111:2433-2443.

Takenawa T, Suetsugu S: The WASP-WAVE protein network: connecting the membrane to the cytoskeleton. Nat Rev Mol Cell Biol 2007;8:37-48.

119 Takai Y, Sasaki T, Matozaki T: Small GTPbinding proteins. Physiol Rev 2001;81:259270.

120 Togawa A, Miyoshi J, Ishizaki H, Tanaka M, Takakura A, Nishioka H, Yoshida H, Doi T, Mizoguchi A, Matsuura N, Niho Y, Nishimune Y, Nishikawa S, Takai Y: Progressive impairment of kidneys and reproductive organs in mice lacking Rho GDIalpha. Oncogene 1999;18:5373-5380.

21 Gorovoy M, Neamu R, Niu J, Vogel S, Predescu D, Miyoshi J, Takai Y, Malik A, Voyno-Yasenetskaya T: RhoGDI-1 modulation of the activity of monomeric RhoGTPase RhoA regulates endothelial barrier function in mouse lungs. Circ Res 2007;101:5058.

122 Zhang H, Cybulsky AV, Aoudjit L, Zhu J, Li $\mathrm{H}$, Lamarche-Vane N, Takano T: Role of Rho-GTPases in complement-mediated glomerular epithelial cell injury. Am J Physiol Renal Physiol 2007;293:F148F156.

123 Yeatman TJ: A renaissance for SRC. Nat Rev Cancer 2004;4:470-480.

24 Thiery JP, Sleeman JP: Complex networks orchestrate epithelial-mesenchymal transitions. Nat Rev Mol Cell Biol 2006;7:131142. 